\title{
The Role of Contrast Enhanced Computed Tomography in Integrated Positron Emission Tomography Computed Tomography Study
}

\author{
Abdul Jalil Nordin ${ }^{1}$, Noraini Abdul Rahim², \\ Fathinul Fikri Ahmad Saad ${ }^{1}$ and Ahmad Zaid Fattah Azman ${ }^{1}$ \\ ${ }^{1}$ Diagnostic Nuclear Imaging Centre, Universiti Putra Malaysia, Serdang \\ ${ }^{2}$ Radiology Department, Serdang Hospital, Serdang \\ Malaysia
}

\section{Introduction}

Integrated Positron Emission Tomography Computed Tomography (PET/CT) is becoming an important tool for clinical investigation with increase clinical utilization. Technology evolution has brought tremendous improvement in lesion detection by integrating morphological and functional informations in a single study. Improved technical specification for CT and PET camera is translated into shorter time spent in image acquisition and reconstruction with improved PET temporal resolution. Both systems complement each other in improving diagnostic capabilities by enabling accurate lesion localization unlike stand alone PET or CT system .

A combined PET/CT system involves the use of a full-ring detector PET scanner with a multi-detector helical CT scanner in combination, allowing the PET scan to be acquired sequentially after the CT scan. The images are then fused to give a precise localization of PET-positive lesions. When integrated PET/CT system was initially introduced, CT scan was performed using low dose exposure without intravenous contrast administration.

This new integrated technology imaging diagnostic system improved lesion detectability, localization, and characterization in up to $30 \%$ of 204 cases as demonstrated by Rachel and her colleague (1). The greatest impact was in abdominal and pelvic diagnostic interpretations than any other sites.

To optimize the diagnostic capability of both systems during an integrated PET/CT study, variations to the basic CT practice has been employed.(2). In addition to useful diagnostic informations obtained, the advantage of advance CT protocol can be observed in cases where lesions are non PET-avid, and alternative diagnostic imaging study is needed. Thus, higher diagnostic CT quality performed during integrated PET/CT study will avoid the hassle for a separate diagnostic CT appointment.

This chapter will highlight the advantages of contrasted CT over low dose CT in a contemporaneous integrated FDG PET/CT study. The capability of both modalities would be optimized if such technique is employed. The technical aspects of multi detector CT and PET and the specifications are discussed elsewhere. 


\section{PET technique - Basic and advance}

\subsection{Basic PET technique}

PET is a nuclear imaging technique which detects abnormal tissues with the help of molecular imaging probe like flurodeoxyglucose (FDG), dopa, fluoroethylcholine (FLT) and fluoroethylthymidine (FET). These probes can be tagged with radioisotopes like 18-Fluorine $\left({ }^{18} \mathrm{~F}\right)$ and carbon $\left({ }^{11} \mathrm{C},{ }^{12} \mathrm{C}\right)$. These unstable isotopes while emitting beta plus $\left(\beta^{+}\right)$rays will enable the PET camera to localize the highest decaying activity in the body. The process can be captured and image. However, due to poor resolution of PET camera, a standalone PET system yields poor lesion localization. To improve the resolution, transmission from Germanium-68 isotope was utilized for attenuation correction but the technique is time consuming. All new PET systems are now improved by incorporation with a CT system. The CT parameters are used for attenuation correction of PET images. The new integrated system is capable in delivering higher quality images with improved resolution (Figure 1) . The time spent for each examination is shorter in comparison to using the conventional old PET system.

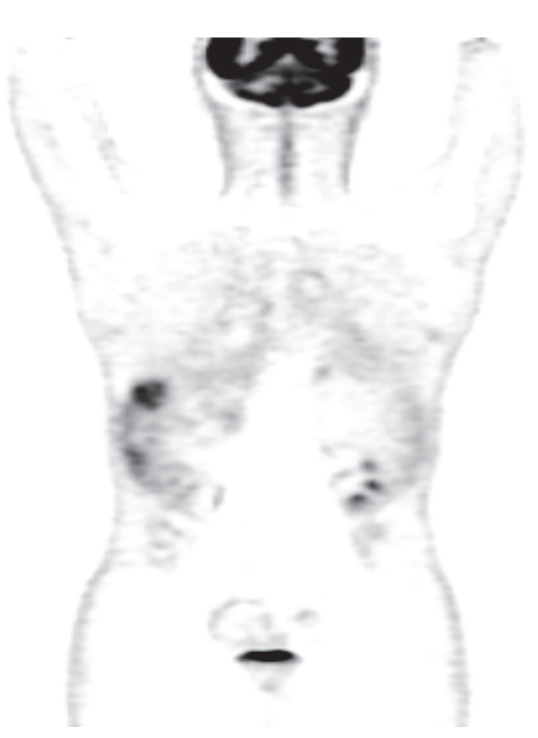

(a)

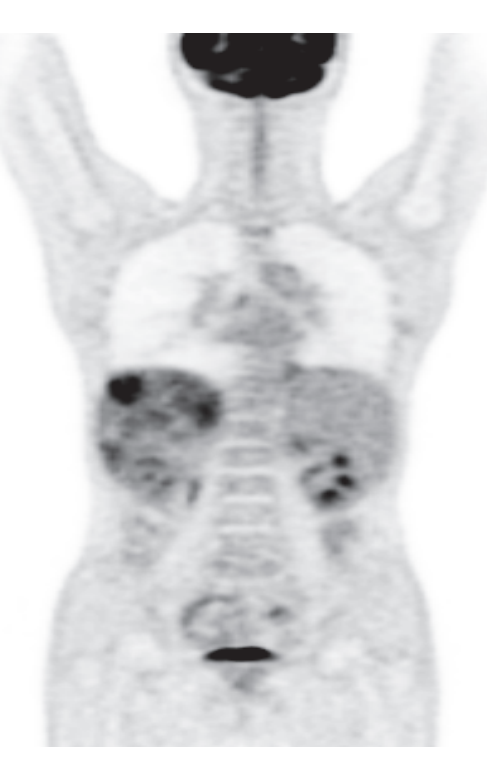

(b)

Fig. 1. Coronal view of PET image in grey scale demonstrating non attenuation corrected image (a) and attenuation corrected image (b) using CT parameters.

The widely recommended protocol for a PET study is intravenous injection of 8-12mci of 18F-FDG isotope after ensuring that the patient is fasting by obtaining fasting blood sugar. Prior to intravenous administration of isotope, the height and weight of the patient will also be recorded. These essential parameters are important for accurate calculation of standardized uptake value (SUV), a recognized method in semiquantifying the FDG uptake in avid lesions. PET/CT image acquisition will start after 45 minutes post injection rest to ensure good FDG uptake and distribution in the body. Image acquisition will start with a 
scanogram for planning the study followed by low dose CT from eyes to the thigh with exception in cases of melanoma and childrens. Images acquired in 2D or 3D mode with 2-3 minutes per bed position ending with 5-7 bed positions will depend on the dose of isotope injected and size of the patient. Tall patients may require more time to complete the eyes and thigh protocol as compared to shorter individuals.

This recommended basic PET imaging technique is practiced with minor variation from one institution to another depending on camera specification and work load.

\subsection{Advance PET technique}

Advance whole body FDG PET study includes delayed or dual- time point imaging techniques.

In delayed PET image acquisition technique, imaging is delayed after 90 minutes following an earlier acquisition at 45 minutes (3).Russ et al observed a significant increase in standard uptake value (SUV) of liver lesions between early and delayed acquisition $(p<0.001)$ in 30 patients without significant reduction in liver background activity between the two studies allowing better lesion detection by visual inspection. Delayed phase PET protocol also revealed new lesions in $17 \%$ of the patients thus improved lesion detectability in primary and metastatic liver disease. Thus, the technique may be deemed beneficial in oncology work-up to obtain detail information on extension of lesions .

Another advance PET technique is the dual-time point imaging. The technique has been utilized to differentiate inflammatory from malignant lesions $(4,5,6)$. Lesion of inflammatory in origin demonstrate peak FDG uptake at approximately 30 minutes post FDG injection. As opposed to aggressive malignant lesions which peak is seen much later depending on histopathological variation and degree of aggressiveness.

\section{Contrast Enhanced Computed Tomography (CECT)}

Computed tomography is a diagnostic radiological imaging modality commonly employed to assist physicians in the clinical management. CT is a useful tool in cancer staging, localizing infection and inflammatory lesions and evaluation of treatment response. In clinical practice, a stand- alone CT system is often the first choice of cross sectional imaging modality to be employed in making a diagnosis. This is attributed to its accessibility, fast, relatively cheap and its capability in demonstrating morphological abnormalities. In addition, CT procedures are somehow standardized and reproducible.

Technological development focusing on CT helical systems resulted in increased gantry speed rotation, increasing number of detector rows, and increased tube outputs to maintain adequate signal-to-noise ratio (SNR) leading to improved image resolution. New development involving PET systems are now incorporated into multidetector CT with full diagnostic capability.

In this section, we highlight the benefit of using contrast enhanced CT during integrated FDG PET/CT study.

Although low dose CT has been an acceptable norm in PET/CT practice, contrast enhanced CT integrated with PET can be considered as the protocol of choice in recent days especially if the technique will benefit the patient's clinical management .

Advance CT protocol is useful in demonstrating pathology accurately. This can be achieved through dynamic and sequential image acquisition protocols to be incorporated into multiplanar PET images. The technique is capable in characterizing tumour physiology with improved 
visual delineation of tumour margins (7). Inflammatory lesions and infection can also be highlighted and shall gain advantage from this technique. The new multidetector CT scanners can achieve a high temporal resolution in monitoring contrast agent first-pass effects(8).

Lesion characterization on CT are through morphological changes, homogeneity, size, outline, vascularity and adjacent structure involvement. Lesion characterization through enhancement properties depends on whether they are hyper or hypovascular in nature as different types of lesions enhance differently during each phase of image acquisition.

\begin{tabular}{|c|c|c|c|}
\hline MAs & Very Low Dose CT & Intermediate dose CT & Diagnostic CT \\
\hline Description 35 & $40-80 \mathrm{mAs}$ & $>80 \mathrm{mAs}$ \\
\hline $\begin{array}{c}\text { No oral, rectal, } \\
\text { intravenous contrast }\end{array}$ & $\begin{array}{c}\text { Oral and rectal } \\
\text { contrast may be } \\
\text { administered }\end{array}$ & $\begin{array}{c}\text { Oral, rectal , } \\
\text { intravenous contrast } \\
\text { administrered }\end{array}$ \\
\hline
\end{tabular}

Table 1. Recommended CT doses during whole body FDG PET/CT study

There is increasing evidence in the literature to support the incremental benefit of FDGPET/ CT in tumour staging and monitoring treatment response. The latest generation of $\mathrm{PET} / \mathrm{CT}$ machines incorporates multi-detector $\mathrm{CT}$ allowing diagnostic quality $\mathrm{CT}$ images to be obtained. As such, CT images acquired during integrated PET/CT examination can be used to avoid separate CT examination for staging or treatment response assessment. Lowdose CT protocols allow attenuation-correction of PET images and accurate anatomical localization. However, image quality is compromised with poor resolution and inability to exclude an involvement of surrounding organs and vascular structures. Informations obtained at visual image interpretation are vital informations to support clinical decisions. It is also vital consideration to the non-specificity of fluorodeoxyglucose (FDG) to malignant lesions. Some malignancies demonstrate poor or non FDG-avidity. In these circumstances, an alternative imaging modality is needed. Integrated diagnostic contrast enhance-CT during PET/CT study potentially avoid another CT session which is inconvenient to the patient which lead to delay in diagnosis and treatment delivery. This can be avoided if a diagnostic $\mathrm{CT}$ is integrated concurrently with PET imaging in a single seating.

A diagnostic CT procedure incorporated in a PET/CT study may comprise either a single phase or a multiphase contrast enhanced CT. Image acquisition during a single phase study starts $60-80$ s following bolus intravenous contrast administration at a rate of $2-3 \mathrm{mls} /$ second while multiphase CT comprise of arterial, venous and delayed phase CT where images are acquired at different time frame.

During study of patient with suspicious intracranial pathology, physiological high intracerebral FDG uptake will mask the visibility of lesions. Contrasted CT image acquisition during the study can potentially identify intracranial structural abnormalities (figure 2).

Non invasive CT angiography of cerebral circulation can be a useful technique for demonstrating vascular involvement. This technique can be incorporated into a PET/CT study mapping the course of nearby vessels. The information is useful in excluding specific vascular involvement and choosing the correct vessel for intra arterial embolization procedures.

In head and neck malignancy involving the neck nodes, contrasted CT during FDG PET/CT study can provide useful information prior to CT guided histo-pathological sampling procedure in establishing the clinical diagnosis. 


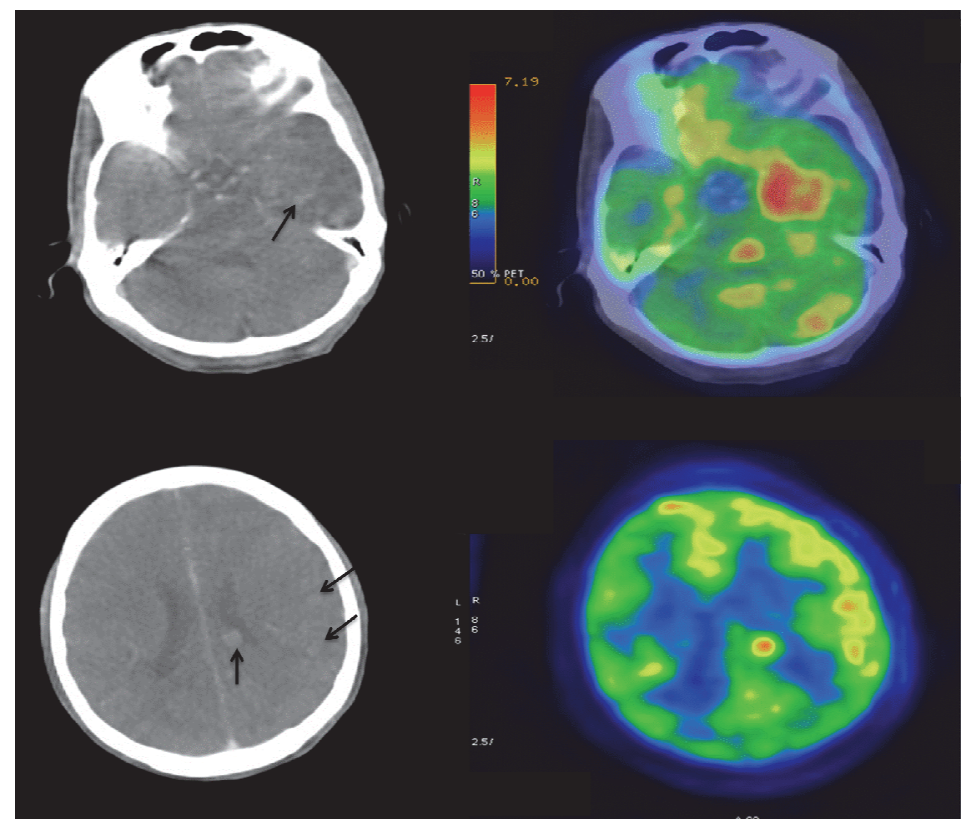

Fig. 2. Single phase contrast enhanced PET CT in a 28-year old man demonstrating subtle enhancing intracerebral (black arrows) tuberculosis abcess in the brain.

In thoracic malignancy, particularly carcinoma of the lungs involving mediastinal nodes, contrast enhanced PET/CT study can be a useful technique in affirming T-staging by excluding local invasion, guiding invasive interventional tissue sampling procedure by avoiding vital structures and characterizing tumour resectability (figure 3).

A single phase PET/contrast enhance CT can also be carried out in patients with mediastinal malignancy including carcinoma of esophagus (figure 4).

A 4- phase CT technique involves CT image acquisition at different time phases including a plain non contrasted study prior to contrast administration, arterial phase (30 seconds delay imaging), venous phase (70-90 seconds delay imaging) and delayed phase (5-10 minutes delay imaging ). Technical softwares are usually available in prescribing the protocol depending on the type and specification of the equipment. These include smartprep, carebolus or bolus tracking.

$\mathrm{CT}$ is a valuable tool in assessing liver pathology. Informations acquired is very useful in planning clinical management especially in cases of hepatocellular carcinoma and metastasis. A 4- phase CT liver and a single phase CT can be used in the former and latter conditions respectively.

FDG avidity of hepatocellular carcinoma in PET imaging varies. Most of the time they demonstrate low avidity except in aggressive tumour sub-types which usually demonstrate higher uptake and activity. Similar to metastatic lesions where tumours with tendency to develop cystic liver metastasis will demonstrate low FDG avidity than the more aggressive solid liver lesions. In the event of non FDG-avid or unidentified malignant liver lesions during a PET/CT study, an alternative imaging modality is sought for to help solving the clinical diagnosis (figure 5). 

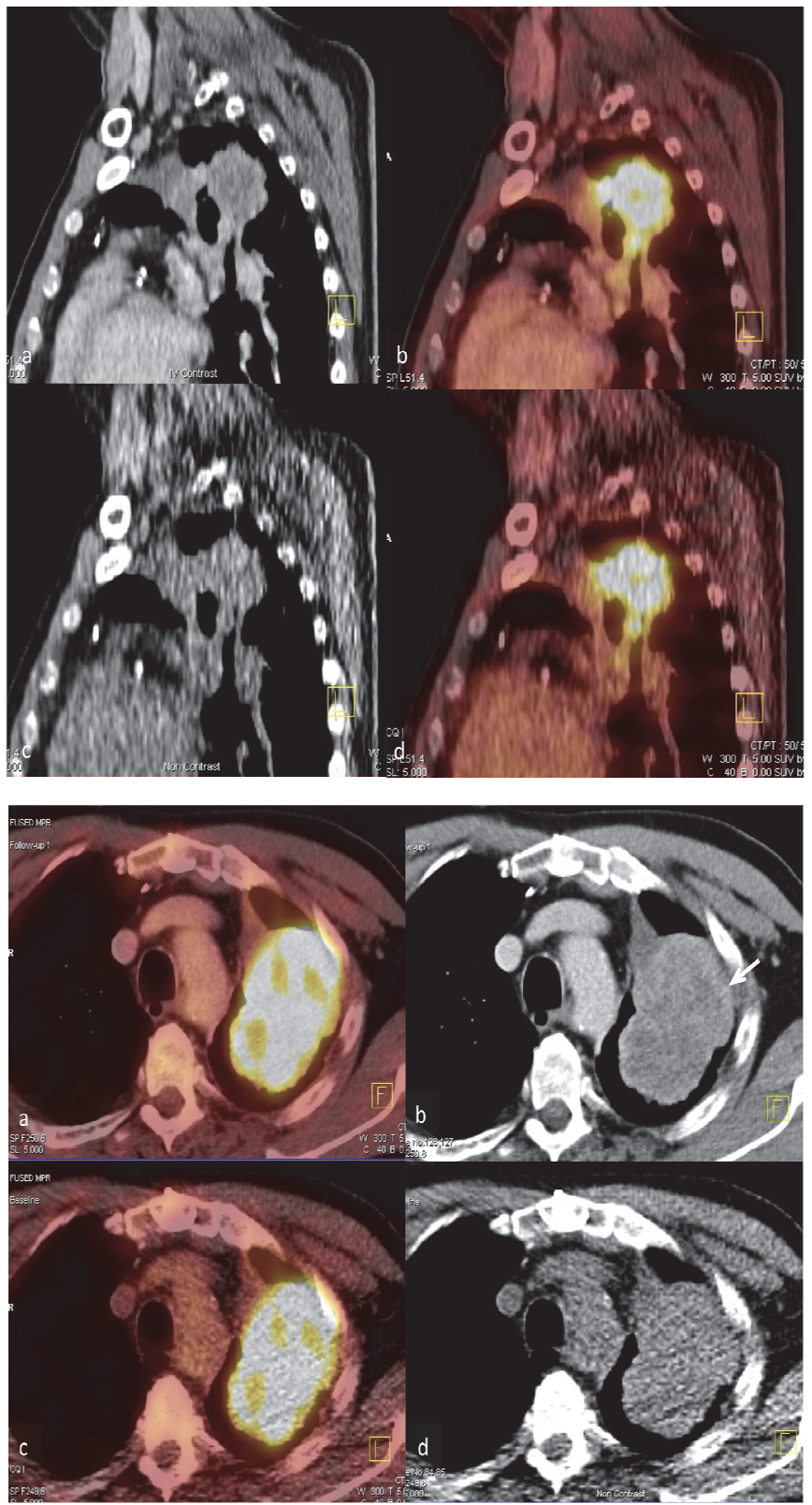

Fig. 3. FDG PET/CT study of a 56 year old man with carcinoma of the left lung. FDG PET study in sagittal (top) and axial (bottom). Top row (a and b) demonstrate PET/CT study with intravenous contrast administration and bottom row (c and d) demonstrate FDG PET/CT with low dose non contrasted CT. Intravenous contrast sharply delineating tumour outline ( white arrow axial CT image) excluding thoracic wall invasion and vascular involvement. 


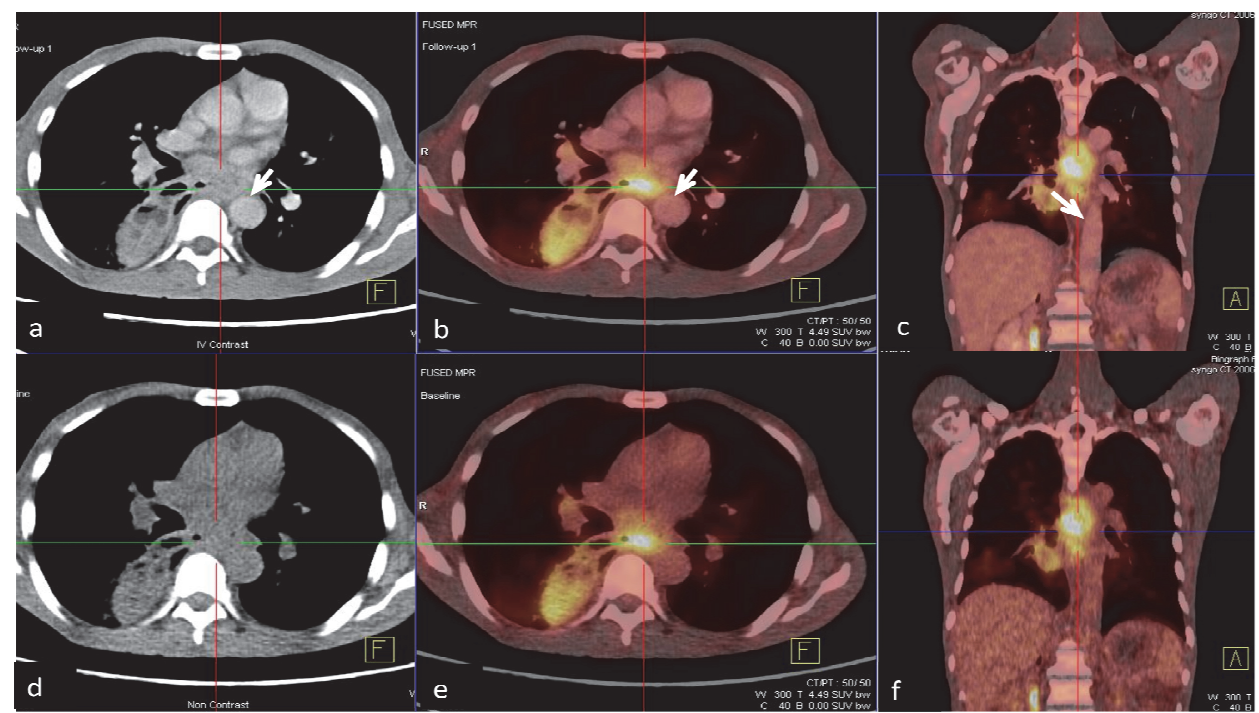

Fig. 4. Whole body FDG PET/CT study showing contrast enhanced CT $(a, b, c)$ and non contrast enhanced $\mathrm{CT}(\mathrm{d}, \mathrm{e}, \mathrm{f})$ in a patient diagnosed with carcinoma of esophagus. In axial and coronal planes $(\mathrm{c}, \mathrm{f})$. Poor definition of descending aortic wall in non enhanced CT was solved after giving intravenous contrast administration (white arrow). Contrast enhanced CT helped in determining tumour resectability and treatment planning in this patient

18F-FDG-PET in combination with low dose CT in the evaluation of hepatocellular carcinoma has low sensitivity (55\%) in comparison to multiphase contrast enhanced CT $(90 \%)$. Since the role of PET in detecting primary carcinoma is limited, contrasted multiphase CT during PET/CT study can be a very useful protocol in detecting liver pathology (9).

The accuracy of low dose CT during qualitative assessment of the liver can be jeorpardized in cases where the $\mathrm{CT}$ value of the lesions fall within the range of normal liver parenchyma. In such situation, contrast enhanced CT can delineate these lesions through enhancing pattern of normal liver parenchyma against the lower attenuation value of the lesion itself rendering visibility of the lesions separable from the normal liver parenchyma $(10,11,12,13)$. The successful use of contrast enhanced CT during PET/CT examination has been clearly demonstrated by Patrick VH and his colleagues. In his study, he reported the integration of a combined CT-perfusion in FDG PET study without the use of additional contrast media compared to a standard contrast enhance PET/CT study in patients with intra abdominal malignancy (14).

CT is more sensitive than FDG-PET in detecting colorectal metastases following neoadjuvant therapy. According to Lubezky and his group (15), the sensitivity of CT in comparison to FDG PET is $65 \%$ versus $49 \%(n=27 ; \mathrm{p}<0.0001)$. The lower sensitivity of FDG PET in detecting liver metastasis during this time are attributed by various factors including post-chemotherapeutic 'metabolic shutdown' phenomenon, small size lesions and non FDG avidity. Baseline FDG PET/CT studies prior to neo-adjuvant therapy in colorectal cancer patients are known to be mandatory, thus contrast enhanced CT during this time may 
deemed appropriate. From the study conducted by Lubezky, the technique is obviously beneficial in demonstrating non avid smaller liver lesions which may be limited by PET camera's spatial resolution.

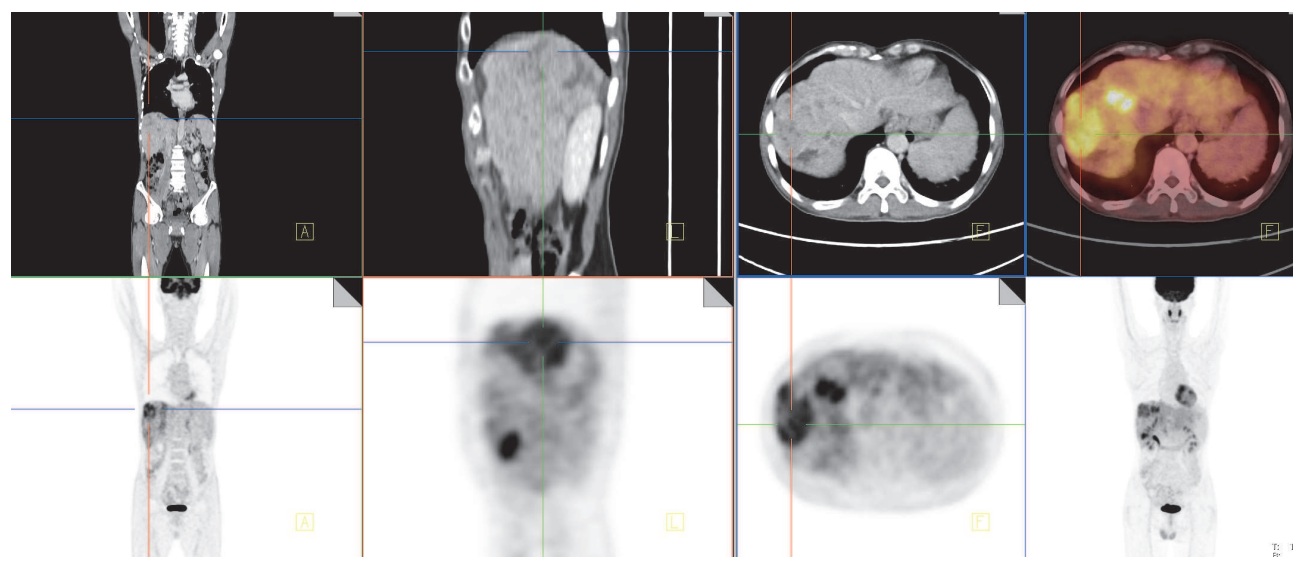

a. FDG PET/CT study using intravenous non ionic contrast enhanced CT

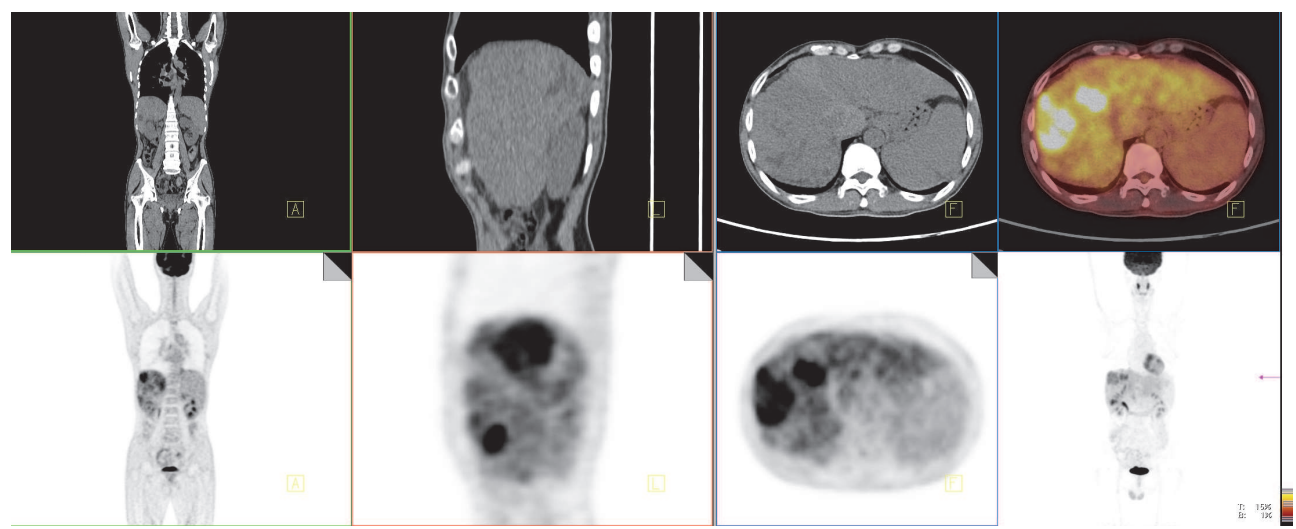

b. FDG PET/CT study with low dose CT

Fig. 5. Multiplanar images acquired for a 56 year old patient diagnosed with hepatocellular carcinoma in FDG PET/CT study using intravenous contrast (a), and using low dose CT (b). There are multifocal high metabolic activity lesions seen in segment VIII of the liver clearly demonstrate in the study as ill defined heterogenous contrast enhancement within the affected segment (a) as compared to low dose CT (b).

As an alternative to using positive contrast media during PET/CT study, negative contrast like gas can also be used. In the assessment of intraabdominal malignancy arising from the bowels, cross-sectional imaging study of the bowels using CT is capable in demonstrating the entire intraluminal, wall thickness and extraluminal involvement $(16,17)$.

Non invasive virtual CT colonoscopy (VCTC) using thin-slice cross-sectional imaging techniques with multiplanar 3D reconstruction is another procedure capable in evaluating 
the entire large bowel. The technique has positive impact in screening patients with intermediate risk for malignant colonic polyps $(18,19)$. Integrating VCTC with FDG PET will perfect the diagnostic value of both modalities. This technique may be useful especially in the evaluation of focal increase bowel activity commonly addressed as physiological bowel uptake $(20,21)$. The sensitivity and specificity of VCTC in detecting polyps ranging between $48-85 \%$ and $91-97 \%$ depending on polyp size (Mulhall et al) while the sensitivity of FDG PET to detect pre-malignant adenomatous polyps also correlated with grading of polyp dysplasia (20) and generally non pre-malignant hyperplastic polyps do not tend to be FDG avid. The intensity of FDG uptake is also incapable to discriminate malignant, premalignant and benign lesions $(23,24)$. Thus incidental focal colonic uptake on PET deserves further confirmatory investigations to exclude a malignant pathology. CT can play an important role in localizing these lesions.

The advantage of combining VCTC into FDG PET study has been proven by Veit-Haibach and his colleagues where the tehnique improved the accuracy of staging in 47 patients with colorectal carcinoma (25).

Integrated PET/ low dose CT has limited role in local staging of rectal and colonic cancers except in the assessment of metastatic disease and potential recurrence $(26,27)$. The value of diagnostic CT with intravenous contrast can be optimized during integrated imaging PET/CT in rectal and colonic cancers especially in complicated cases of gross invasion of adjacent organs (T4). Contrast enhancement of the surrounding organs of the lesion can assess local invasion. Since CT is routinely employed as a primary tool in the detection of metastatic disease in rectal carcinoma, combining FDG PET and CECT will provide 'one stop shop' for the patient (28)

The feasible role of combined FDG PET/VCTC may also be applicable in combined FDG PET/CT enterography (CTE) which involves enteroclysis using low-density oral contrast agents, intravenous contrast and thin slice CT image acquisition. The technique can be useful in small bowel infections, neoplasms, adhesions, polyps, vascular malformations and inflammatory bowel diseases. (29) The protocol can potentially provide better clues on the cause of pitfalls in FDG PETCT imaging of the bowels which are currently addressed as physiological activity in most cases .

The role of FDG PET / CT cholangiography using biliary excreted contrast agent should be further evaluated (30)

High resolution advanced MDCT technique has become the mainstay of pancreatic tumor imaging. Multiphase CT allow accurate detection, staging and assessment of tumor resectability $(31,32)$. In general, the differentiation of malignant and inflammatory lesions on FDG PET images are crucial, Multiphase CT angiography has the potential to increase the diagnostic value of FDG PET/CT study in pancreatic carcinoma especially in determining tumour resectability by excluding vascular invasion. Contrast enhanced PET/CT is also a recommended imaging procedure in carcinoid and non-carcinoid neuroendocrine tumours (33). In any clinical situation, decision should adhere to ALARA principle. Perhaps, in view of clinical benefits to patients, contrast enhanced FDG PET/CT protocol should be recommended as a first line tool in imaging of selected malignant diseases.

\section{Implications}

\subsection{Radiation dose}

Recent advances in CT equipment has enable high resolution imaging of smaller anatomical structures which has made imaging more feasible for small to medium size vessels but resulting in higher radiation dose delivered to the patients. 
Increasing concern over radiation dose have been addressed by vendors through technical improvement of X-ray tubes (34). Other strategies to reduce dose include the awareness of referring doctors especially the capability of 'one stop shop' of PET CT facilities. These attempts to reduce patients' radiation dose according to the 'As Low As Reasonably Achievable' (ALARA) principle(35). The opportunity to reduce dose exposure should be seize during whole body PET/CT study by optimizing the diagnostic role of contrasted CT. Each PET/CT study would lead to radiation exposure ranging from 14 to $32 \mathrm{mSv}$ in adults depending on CT parameters. The PET component typically contributes $8-9 \mathrm{mSv}$ to the overall radiation dose based on a standard $10 \mathrm{mCi}$ dose of tracer. Importantly, avoiding duplication of studies also reduces overall radiation exposure.

\subsection{Standardized uptake value}

Standardized uptake value (SUV) is the most commonly used method for assessing tumor glucose metabolism in clinical studies (36) where it can be measured with relative ease.

The basic concept underlying the SUV is that the activity concentration after injection is correlated with FDG phosphorylation rates where it is approximately proportionate to the activity concentration in the tissue and inversely correlated to the ratio of the injected dose to the body weight (37).The rate of FDG phosphorylation is a measure to tumor glucose utilization which can be influenced by multiple factors including patient size, blood glucose level, extravascular injection and others (38).

In addition to FDG PET/CT study before the start of treatment, semiquantitative analysis of FDG uptake is also needed in assessing early tumour response during the course of treatment $(39,40)$. This can help differentiate between responders and non responders. The controversial effect of contrasted PET/CT study on SUV readings is highlighted in the following section.

\subsection{Effects of contrasted PET/CT on semiquantitative uptake value (SUV)}

Following the work of Kinahan and his colleagues (39), improved function of PET/CT scanner by CT-attenuation correction eliminated the need for orbiting transmission sources. The quality of joint PET/CT procedure can be improved further by performing contrast enhance study. Thus a separate diagnostic CT scan can be avoided.

Studies from several groups $(41,42,43,44)$ including Berthelsen $(45)$ demonstrated the feasibility of intravenous contrast administration in PET/CT scanning without changing the clinical diagnostic interpretation. These studies demonstrated the effects of intravenous CT contrast in malignancy.

We observed the effect of contrast CT in PET/CT study in 19 patients investigated for infections. In our study, whole body PET/CT scan were conducted using a standard protocol. Two sets of datas where low dose CT and diagnostic contrasted CT were obtained. Both parameters were utilized for attenuation correction of PET images. During image analysis, we compared the percentage difference of CT value in Hounsfield unit (HU) and Standardized Uptake Value (SUV) PET at 4 different anatomical sites including the right lobe of liver, spleen, right heart chamber and urinary bladder. We tabulated our findings and performed statistical analysis.

\section{Result}

The percentage differences of HU and SUV were calculated in all 4 different sites for all patients and tabulated in table 2-6. 


\begin{tabular}{|c|c|c|c|c|c|c|c|c|c|c|c|c|}
\hline \multirow{2}{*}{ No } & \multicolumn{6}{|c|}{ Computed Tomography (CT) } & \multicolumn{6}{|c|}{ Positron Emission Tomography (PET) } \\
\hline & $\begin{array}{c}\text { NECT } \\
\text { mean }\end{array}$ & $\underset{\text { Max }}{\text { NECT }}$ & $\begin{array}{c}\text { CECT } \\
\text { mean }\end{array}$ & $\begin{array}{c}\text { CECT } \\
\text { Max }\end{array}$ & $\begin{array}{c}\text { HUmean } \\
\% \Delta\end{array}$ & $\begin{array}{c}\text { HUmax } \\
\% \Delta\end{array}$ & $\begin{array}{c}\text { NECT } \\
\text { mean }\end{array}$ & $\begin{array}{c}\text { NECT } \\
\text { Max }\end{array}$ & $\begin{array}{l}\text { CECT } \\
\text { mean }\end{array}$ & $\begin{array}{c}\text { CECT } \\
\text { Max }\end{array}$ & $\begin{array}{c}\text { SUVmean } \\
\% \Delta\end{array}$ & $\begin{array}{c}\text { SUVmax } \\
\% \Delta\end{array}$ \\
\hline 1 & 52 & 110 & 89.5 & 127 & -72.1 & -15.5 & 2.6 & 3.7 & 3 & 4.2 & -15.4 & -13.5 \\
\hline 2 & 56 & 136 & 85.4 & 138 & -52.5 & -1.5 & 2.8 & 3.6 & 2.9 & 3.8 & -3.6 & -5.6 \\
\hline 3 & 60.8 & 110 & 107.3 & 164 & -76.5 & -49.1 & 2.3 & 3 & 2.4 & 3.1 & -4.3 & -3.3 \\
\hline 4 & 57.4 & 123 & 100.7 & 165 & -75.4 & -34.1 & 2.4 & 2.9 & 2.2 & 2.8 & 8.3 & 3.4 \\
\hline 5 & 50.8 & 93 & 92.4 & 186 & -81.9 & -100.0 & 3.1 & 3.6 & 2.8 & 3.2 & 9.7 & 11.1 \\
\hline 6 & 54.2 & 124 & 95.3 & 136 & -75.8 & -9.7 & 1.8 & 2 & 1.7 & 2.2 & 5.6 & -10.0 \\
\hline 7 & 58.8 & 83 & 41.5 & 61 & 29.4 & 26.5 & 1.6 & 2.1 & 1.7 & 2 & -6.2 & 4.8 \\
\hline 8 & 33.5 & 114 & 84.3 & 127 & -151.6 & -11.4 & 2.6 & 3.5 & 2.4 & 3.3 & 7.7 & 5.7 \\
\hline 9 & 62.1 & 87 & 98.9 & 128 & -59.3 & -47.1 & 2.2 & 2.5 & 1.9 & 2.4 & 13.6 & 4.0 \\
\hline 10 & 63 & 108 & 124.4 & 193 & -97.5 & -78.7 & 2.2 & 2.8 & 2.3 & 2.7 & -4.5 & 3.6 \\
\hline 11 & 48 & 73 & 86.6 & 120 & -80.4 & -64.4 & 2.5 & 2.9 & 2.1 & 2.9 & 16.0 & 0.0 \\
\hline 12 & 58.8 & 91 & 45.3 & 77 & 23.0 & 15.4 & 2.4 & 3.1 & 2.3 & 3.1 & 4.2 & 0.0 \\
\hline 13 & 44.7 & 74 & 84.6 & 122 & -89.3 & -64.9 & 2.2 & 3 & 2.3 & 2.6 & -4.5 & 13.3 \\
\hline 14 & 105.9 & 798 & 104.1 & 137 & 1.7 & 82.8 & 1.7 & 2.2 & 1.8 & 2.1 & -5.9 & 4.5 \\
\hline 15 & 66 & 89 & 89 & 68.3 & -34.8 & 23.3 & 0.9 & 1.3 & 1.1 & 1.3 & -22.2 & 0.0 \\
\hline 16 & 47.9 & 76 & 105.5 & 128 & -120.3 & -68.4 & 0.9 & 1.2 & 1.2 & 1.5 & -33.3 & -25.0 \\
\hline 17 & 44 & 306 & 134 & 107.1 & -204.5 & 65.0 & 1.1 & 1.3 & 1.1 & 1.4 & 0.0 & -7.7 \\
\hline 18 & 61.4 & 104 & 92.5 & 128 & -50.7 & -23.1 & 2.1 & 3.4 & 2.1 & 2.4 & 0.0 & 29.4 \\
\hline 19 & 53.7 & 123 & 84 & 141 & -56.4 & -14.6 & 1.6 & 2.4 & 1.6 & 2.6 & 0.0 & -8.3 \\
\hline & & & & $\begin{array}{c}\text { mean } \\
\text { sd }\end{array}$ & $\begin{array}{c}-69.7 \\
55.1\end{array}$ & $\begin{array}{c}-19.4 \\
48.1\end{array}$ & & & & $\begin{array}{c}\text { mean } \\
\text { sd }\end{array}$ & $\begin{array}{l}-1.8 \\
12.1\end{array}$ & $\begin{array}{c}0.3 \\
11.4\end{array}$ \\
\hline
\end{tabular}

Table 2. The percentage differences in HU and SUVmax and SUVmean obtained from the right lobe of the liver.

\begin{tabular}{|c|c|c|c|c|c|c|c|c|c|c|c|c|}
\hline \multirow{2}{*}{ No } & \multicolumn{6}{|c|}{ Computed Tomogaphy (CT) } & \multicolumn{6}{|c|}{ Positron Emission Tomography (PET) } \\
\hline & $\begin{array}{l}\text { NECT } \\
\text { mean }\end{array}$ & $\begin{array}{l}\text { NFC.T } \\
\max \end{array}$ & $\begin{array}{c}\text { CECT } \\
\text { mean }\end{array}$ & $\begin{array}{c}\text { CECT } \\
\max \end{array}$ & $\begin{array}{c}\text { HIImean } \\
\% \Delta\end{array}$ & $\underset{\% \Delta \Delta}{H I \max }$ & $\begin{array}{l}\text { NFCT } \\
\text { mean }\end{array}$ & $\begin{array}{c}\text { NECT } \\
\max \end{array}$ & $\begin{array}{c}\text { CFCT } \\
\text { mean }\end{array}$ & $\begin{array}{c}\text { CECT } \\
\max \end{array}$ & $\begin{array}{c}\text { SIVmean } \\
\% \Delta\end{array}$ & $\begin{array}{c}\text { SIJ max } \\
\% \Delta\end{array}$ \\
\hline 1 & 47 & 92 & 118.2 & 183 & -151.5 & -98.9 & 1.5 & 1.8 & 2.1 & 5.9 & -40.0 & -227.8 \\
\hline 2 & 43 & 112 & 121.4 & 164 & -182.3 & -46.4 & 2.1 & 2.8 & 2.2 & 2.7 & -4.8 & 3.6 \\
\hline 3 & 47 & 81 & 154.6 & 188 & -228.9 & -132.1 & 1.5 & 2.1 & 1.7 & 2 & -13.3 & 4.8 \\
\hline 4 & 47.2 & 86 & 130.5 & 159 & -176.5 & -84.9 & 1.9 & 2.3 & 2 & 2.4 & -5.3 & -4.3 \\
\hline 5 & 25.8 & 57 & 153 & 175 & -493.0 & -207.0 & 2 & 2.3 & 1.6 & 1.9 & 20.0 & 17.4 \\
\hline 6 & 39.8 & 70 & 156.3 & 177 & -292.7 & -152.9 & 1.4 & 1.5 & 1.3 & 1.5 & 7.1 & 0.0 \\
\hline 7 & 78.9 & 126 & 42.9 & 56 & 45.6 & 55.6 & 1.5 & 1.6 & 1.5 & 1.7 & 0.0 & -6.2 \\
\hline 8 & 90 & 190 & 142 & 214 & -57.8 & -12.6 & 2.4 & 3.1 & 2.3 & 2.9 & 4.2 & 6.5 \\
\hline 9 & 38.4 & 54 & 148 & 177 & -285.4 & -227.8 & 1.9 & 2.5 & 1.7 & 2.1 & 10.5 & 16.0 \\
\hline 10 & 45.9 & 72 & 145.8 & 175 & -217.6 & -143.1 & 2 & 2.3 & 1.8 & 2.1 & 10.0 & 8.7 \\
\hline 11 & 24.6 & 44 & 118.7 & 187 & -382.5 & -325.0 & 1.7 & 2 & 1.6 & 2 & 5.9 & 0.0 \\
\hline 12 & 30.5 & 60 & 87.2 & 123 & -185.9 & -105.0 & 1.5 & 1.9 & 1.9 & 1.5 & -26.7 & 21.1 \\
\hline 13 & 39.5 & 63 & 133.1 & 165 & -237.0 & -161.9 & 2.6 & 3.5 & 2.5 & 3.2 & 3.8 & 8.6 \\
\hline 14 & 129.8 & 155 & 132.4 & 159 & -2.0 & -2.6 & 1.3 & 1.6 & 1.4 & 1.7 & -7.7 & -6.2 \\
\hline 15 & 68 & 84 & 85.1 & 108 & -25.1 & -28.6 & 1 & 2.5 & 0.8 & 1 & 20.0 & 60.0 \\
\hline 16 & 59.9 & 78 & 172.8 & 197 & -188.5 & -152.6 & 0.6 & 0.9 & 1.1 & 1.4 & -83.3 & -55.6 \\
\hline 17 & 25.4 & 40 & 71.2 & 193 & -180.3 & -382.5 & 0.7 & 1.1 & 1.9 & 10.8 & -171.4 & -881.8 \\
\hline 18 & 69.4 & 131 & 95 & 132 & -36.9 & -0.8 & 1.3 & 1.8 & 1.4 & 1.8 & -7.7 & 0.0 \\
\hline \multirow[t]{3}{*}{19} & 61.8 & 102 & 99.3 & 123 & -60.7 & -20.6 & 1.9 & 2.4 & 2.6 & 2.9 & -36.8 & -20.8 \\
\hline & & & & mean & -175.7 & -117.3 & & & & mean & -16.6 & -55.6 \\
\hline & & & & sd & 134.7 & 113.2 & & & & sd & 44.9 & 208.1 \\
\hline
\end{tabular}

Table 3. The percentage differences in HU and SUVmax and SUVmean obtained from the right heart chamber 


\begin{tabular}{|c|c|c|c|c|c|c|c|c|c|c|c|c|}
\hline \multirow[b]{2}{*}{ No } & \multicolumn{6}{|c|}{ Computed Tomography (CT) } & \multicolumn{6}{|c|}{ Positron Emission Tomography (PET) } \\
\hline & $\begin{array}{l}\text { NECT } \\
\text { mean }\end{array}$ & $\begin{array}{l}\text { NECT } \\
\text { Max }\end{array}$ & $\begin{array}{l}\text { C.ECT } \\
\text { mean }\end{array}$ & $\begin{array}{l}\text { C.ECT } \\
\text { Max }\end{array}$ & $\begin{array}{c}\text { HUJmean } \\
\% \Delta\end{array}$ & $\begin{array}{c}\text { HIJmax } \\
\% \Delta\end{array}$ & $\begin{array}{l}\text { NFCT } \\
\text { mean }\end{array}$ & $\begin{array}{l}\text { NECT } \\
\text { Max }\end{array}$ & $\begin{array}{l}\text { CECT } \\
\text { mean }\end{array}$ & $\begin{array}{c}\text { CECT } \\
\text { Max }\end{array}$ & $\begin{array}{c}\text { SUVmean } \\
\% \Delta\end{array}$ & $\begin{array}{c}\text { SIVmax } \\
\% \Delta\end{array}$ \\
\hline 1 & 42.3 & 75 & 93.3 & 130 & -120.6 & -73.3 & 2.2 & 2.7 & 2.7 & 3.7 & -22.7 & -37.0 \\
\hline 2 & 46.4 & 107 & 86.4 & 128 & -86.2 & -19.6 & 2.4 & 2.7 & 2.5 & 3.2 & -4.2 & -18.5 \\
\hline 3 & 48.2 & 83 & 102.1 & 128 & -111.8 & -54.2 & 2.3 & 3.1 & 2.1 & 2.7 & 8.7 & 12.9 \\
\hline 4 & 44.5 & 75 & 87.2 & 116 & -96.0 & -54.7 & 2.4 & 2.7 & 2.1 & 2.9 & 12.5 & -7.4 \\
\hline 5 & 47.8 & 98 & 99 & 126 & -107.1 & -28.6 & 2.6 & 3.1 & 2.6 & 2.9 & 0.0 & 6.5 \\
\hline 6 & 56.1 & 110 & 99.9 & 122 & -78.1 & -10.9 & 1.8 & 2.2 & 1.7 & 2 & 5.6 & 9.1 \\
\hline 7 & 61.8 & 79 & 45.1 & 61 & 27.0 & 22.8 & 1 & 1.3 & 1.2 & 1.4 & -20.0 & -7.7 \\
\hline 8 & 38.7 & 79 & 88.3 & 124 & -128.2 & -57.0 & 2.6 & 3 & 2.8 & 3.4 & -7.7 & -13.3 \\
\hline 9 & 45.8 & 71 & 96.3 & 119 & -110.3 & -67.6 & 1.8 & 2.3 & 1.8 & 2.1 & 0.0 & 8.7 \\
\hline 10 & 50 & 86 & 118.4 & 161 & -136.8 & -87.2 & 2.4 & 2.7 & 2.4 & 2.7 & 0.0 & 0.0 \\
\hline 11 & 44.3 & 71 & 90.3 & 129 & -103.8 & -81.7 & 2 & 2.3 & 1.9 & 2.6 & 5.0 & -13.0 \\
\hline 12 & 68.1 & 99 & 47.9 & 73 & 29.7 & 26.3 & 1.7 & 2.2 & 1.7 & 2 & 0.0 & 9.1 \\
\hline 13 & 52.6 & 74 & 97.4 & 125 & -85.2 & -68.9 & 1.9 & 2.6 & 1.8 & 2.4 & 5.3 & 7.7 \\
\hline 14 & 92.9 & 114 & 95.2 & 130 & -2.5 & -14.0 & 1.5 & 1.7 & 1.5 & 1.8 & 0.0 & -5.9 \\
\hline 15 & 66.7 & 91 & 67.1 & 83 & -0.6 & 8.8 & 1.2 & 2.1 & 1.1 & 1.4 & 8.3 & 33.3 \\
\hline 16 & 51.7 & 70 & 106.6 & 123 & -106.2 & -75.7 & 1.5 & 1.9 & 1.6 & 1.9 & -6.7 & 0.0 \\
\hline 17 & 47.2 & 633 & 102 & 123 & -116.1 & 80.6 & 1.4 & 2.8 & 1.5 & 1.6 & -7.1 & 42.9 \\
\hline 18 & 61.8 & 110 & 77.8 & 125 & -25.9 & -13.6 & 2.1 & 3.2 & 1.7 & 2.5 & 19.0 & 21.9 \\
\hline \multirow[t]{3}{*}{19} & 50 & 107 & 72.9 & 129 & -45.8 & -20.6 & 1.4 & 1.8 & 1.4 & 2.3 & 0.0 & -27.8 \\
\hline & & & & mean & -73.9 & -31.0 & & & & mean & -0.2 & 1.1 \\
\hline & & & & $\mathrm{sd}$ & 53.7 & 44.4 & & & & sd & 10.1 & 19.6 \\
\hline
\end{tabular}

Table 4. The percentage differences in HU and SUVmax and SUVmean obtained from the spleen.

\begin{tabular}{|c|c|c|c|c|c|c|c|c|c|c|c|c|}
\hline \multirow{2}{*}{ No } & \multicolumn{6}{|c|}{ Computed Tomography (CT) } & \multicolumn{6}{|c|}{ Positron Emission Tomography (PET) } \\
\hline & $\begin{array}{l}\text { NECT } \\
\text { mean }\end{array}$ & $\begin{array}{l}\text { NECT } \\
\text { Max }\end{array}$ & $\begin{array}{l}\text { CECT } \\
\text { mean }\end{array}$ & $\begin{array}{l}\text { CECT } \\
\text { Max }\end{array}$ & $\begin{array}{c}\text { HUmean } \\
\% \Delta\end{array}$ & $\underset{\% \Delta}{\text { HUmax }}$ & $\begin{array}{l}\text { NECT } \\
\text { mean }\end{array}$ & $\begin{array}{c}\text { NECT } \\
\text { Max }\end{array}$ & $\begin{array}{l}\text { CECT } \\
\text { mean }\end{array}$ & $\begin{array}{l}\text { CECT } \\
\text { Max }\end{array}$ & $\begin{array}{c}\text { SUVmean } \\
\% \Delta\end{array}$ & $\begin{array}{c}\text { SUVmax } \\
\% \Delta\end{array}$ \\
\hline 1 & -1.2 & 45 & 16.9 & 47 & 1508.3 & -4.4 & 7.9 & 9.7 & 7.7 & 9.8 & 2.5 & -1.0 \\
\hline 2 & 1.8 & 105 & 0.8 & 40 & 55.6 & 61.9 & 6.3 & 8.1 & 6.8 & 8 & -7.9 & 1.2 \\
\hline 3 & -4 & 42 & 6.3 & 33 & 257.5 & 21.4 & 5.8 & 6.6 & 5.9 & 6.7 & -1.7 & -1.5 \\
\hline 4 & -4.7 & 37 & 2.3 & 37 & 148.9 & 0.0 & 4.4 & 5.2 & 4.4 & 5.2 & 0.0 & 0.0 \\
\hline 5 & 8.8 & 51 & 6.5 & 26 & 26.1 & 49.0 & 12.6 & 13.4 & 12.7 & 13.4 & -0.8 & 0.0 \\
\hline 6 & -1 & 62 & -7.5 & 21 & -650.0 & 66.1 & 4.2 & 4.7 & 4.1 & 4.6 & 2.4 & 2.1 \\
\hline 7 & -1.3 & 25 & 1.8 & 20 & 238.5 & 20.0 & 3.5 & 3.8 & 3.5 & 3.8 & 0.0 & 0.0 \\
\hline 8 & -4.3 & 26 & -5.7 & 56 & -32.6 & -115.4 & 5.2 & 6.2 & 5.3 & 6 & -1.9 & 3.2 \\
\hline 9 & -1.4 & 19 & 5.4 & 23 & 485.7 & -21.1 & 5.5 & 6.9 & 5.7 & 7 & -3.6 & -1.4 \\
\hline 10 & 4.2 & 38 & -2.2 & 15 & 152.4 & 60.5 & 5.2 & 6 & 4.6 & 5.3 & 11.5 & 11.7 \\
\hline 11 & -4.6 & 21 & 0.5 & 28 & 110.9 & -33.3 & 7.3 & 7.8 & 7.6 & 8.9 & -4.1 & -14.1 \\
\hline 12 & 11.8 & 43 & 5.6 & 32 & 52.5 & 25.6 & 11.3 & 12.8 & 11.9 & 13.1 & -5.3 & -2.3 \\
\hline 13 & -2.3 & 26 & 32.7 & 67 & 1521.7 & -157.7 & 2.8 & 3.8 & 2.6 & 3.1 & 7.1 & 18.4 \\
\hline 14 & 41.2 & 82 & 38.4 & 70 & 6.8 & 14.6 & 3.1 & 3.5 & 2.9 & 3.1 & 6.5 & 11.4 \\
\hline 15 & 0.5 & 48 & 81.3 & 113 & -16160.0 & -135.4 & 1.9 & 2.6 & 1.8 & 2.5 & 5.3 & 3.8 \\
\hline 16 & -2.8 & 18 & 34.1 & 55 & 1317.9 & -205.6 & 2.1 & 2.6 & 2 & 2.4 & 4.8 & 7.7 \\
\hline 17 & -1.8 & 16 & 28.7 & 58 & 1694.4 & -262.5 & 2.2 & 2.5 & 2.2 & 3.4 & 0.0 & -36.0 \\
\hline 18 & 8.1 & 63 & 8.9 & 66 & -9.9 & -4.8 & 2.1 & 2.7 & 2.1 & 2.7 & 0.0 & 0.0 \\
\hline \multirow[t]{3}{*}{19} & 64.6 & 199 & 14.8 & 103 & 77.1 & 48.2 & 6.6 & 8.6 & 5.7 & 7.4 & 13.6 & 14.0 \\
\hline & & & & mean & -484.1 & -30.1 & & & & mean & 1.5 & 0.9 \\
\hline & & & & $\mathrm{sd}$ & 3849.6 & 97.3 & & & & $\mathrm{sd}$ & 5.6 & 11.5 \\
\hline
\end{tabular}

Table 5. The percentage differences in HU and SUVmax and SUVmean obtained from the bladder

The average mean and the maximum percentage differences were calculated and tabulated as following: 


\begin{tabular}{|c|c|c|c|c|}
\hline \multirow{2}{*}{ Site } & \multicolumn{2}{|c|}{ Computed Tomography } & \multicolumn{2}{c|}{ Positron Emission Tomography } \\
\cline { 2 - 5 } & $\% \Delta$ HUmean & $\% \Delta$ HUmax & $\% \Delta$ SUVmean & $\% \Delta$ SUVmax \\
\hline Liver & 71.6 & 19.5 & 2.1 & 0.9 \\
Spleen & 78.4 & 32.7 & 1.4 & -1.6 \\
Heart & 190.7 & 129.9 & 2.3 & 10.4 \\
Bladder & 545 & 36.2 & -0.9 & -0.2 \\
\hline
\end{tabular}

Table 6. The average mean and maximum percentage differences in all sites.

\section{Statistical analysis}

Nineteen patients were subjected to Non-Contrast Enhanced CT (NECT), Contrast Enhanced CT (CECT), Non-Contrast Enhanced PET (NEPET) and Contrast Enhanced PET (CEPET). For analyses purpose, the clinically-relevant and quantifiable HU-Mean and SUV-Max were treated as unit values of observations for CT (NECT \& CECT) and PET (NEPET \& CEPET) respectively. Observations between Non-Contrast Enhanced and Contrast Enhanced were not treated as independent of each other because the changes in unit values of Contrast Enhance depended on the initial unit values (Non-Contrast Enhanced) of each patient. Thus, values of CT HU-Max (i.e. NECT and CECT) were treated as paired data. Values of PET SUV-Max (i.e. NEPET and CEPET) were also treated as paired data. All HU-Mean and SUV-Max values were originally continuous data but subsequently ranked as most did not conform to Gaussian distribution. Observations of NECT were compared against CECT and observations of NEPET were compared against CEPET. Medians and Interquartile Ranges (IQR) were used as summary measures for HU-Means, SUV-Maxes and percentage of change in HU-Means and SUV-Maxes. Non-parametric (Wilcoxon Signed Ranks) test were used. Alpha $(\alpha)$ was set at 0.05 thus statistical significance was achieved where $p$-value was less than 0.05 . Summary results are shown in Table 7. Graphic comparison between Non-Contrast Enhanced and Contrast Enhanced observations were also shown in figure 6-9.

\section{Interpretation}

At 3 different sites (Liver, Heart \& Spleen), we are able to show that the HU-Mean of NonContrast Enhanced CT (NECT) differ than that of Contrast Enhanced CT (CECT). This difference is statistically significant, $p<0.05$ (Table 7). In other words, administrations of contrast in CT will yield higher HU-Mean values than plain CT (without contrast). In the liver, the median increase in HU-Mean is $75.4 \%(+/ 38.6 \%)$. Results of observations in the heart and spleen also showed similar trend. Only in the bladder the values of HU-Mean did not differ statistically $(p=0.147)$. 


\begin{tabular}{|c|c|c|c|c|}
\hline \multirow{2}{*}{ SITE } & \multirow{2}{*}{$\begin{array}{c}\text { IMAGING TEST } \\
\text { (Values Used) }\end{array}$} & HU-Mean/SUV-Max & $\begin{array}{c}\% \text { Change in } \\
\text { HU-Mean/SUV-Max }\end{array}$ & \multirow{2}{*}{$p$-value } \\
\hline & & Median(IQR) & Median(IQR) & \\
\hline \multirow{5}{*}{ LIVER } & NECT (HU-Mean), n=19 & $56(13.4)$ & \multirow{2}{*}{$75.4(38.6)$} & \multirow{2}{*}{$<0.001^{*}$} \\
\hline & CECT (Hu-Mean), n=19 & $92.4(19.5)$ & & \\
\hline & & & & \\
\hline & NEPET (SUV-Max), n=19 & $2.9(1.3)$ & \multirow{2}{*}{$0(12.5)$} & \multirow{2}{*}{0.814} \\
\hline & CEPET (SUV-Max), n=19 & $2.6(1.0)$ & & \\
\hline \multirow{5}{*}{ HEART } & NECT (HU-Mean), n=19 & $47(29.6)$ & \multirow{2}{*}{$182.3(179.2)$} & \multirow{2}{*}{$<0.001^{*}$} \\
\hline & CECT (HU-Mean), n=19 & $130(53.0)$ & & \\
\hline & & & & \\
\hline & NEPET (SUV-Max), n=19 & $2.1(0.9)$ & \multirow{2}{*}{$0(14.9)$} & \multirow{2}{*}{0.876} \\
\hline & CEPET (SUV-Max), n=19 & $2(2.2)$ & & \\
\hline \multirow{5}{*}{ SPLEEN } & NECT (HU-Mean), n=19 & $50(16)$ & \multirow{2}{*}{$96.0(86.0)$} & \multirow{2}{*}{$0.001^{*}$} \\
\hline & CECT (HU-Mean), n=19 & $93.3(22.1)$ & & \\
\hline & & & & \\
\hline & NEPET (SUV-Max), n=19 & $2.6(0.7)$ & \multirow{2}{*}{$0(80.0)$} & \multirow{2}{*}{0.721} \\
\hline & CEPET (SUV-Max), n=19 & $2.4(1.0)$ & & \\
\hline \multirow{5}{*}{ BLADDER } & NECT (HU-Mean), n=19 & $-1.2(10.9)$ & \multirow{2}{*}{$-110.9(12854.4)$} & \multirow{2}{*}{0.147} \\
\hline & CECT (HU-Mean), n=19 & $6.3(27.9)$ & & \\
\hline & & & & \\
\hline & NEPET (SUV-Max), n=19 & $6(4.6)$ & $0(01)$ & 0 \\
\hline & CEPET (SUV-Max), n=19 & $5.3(4.9)$ & $0(9.1)$ & 0.440 \\
\hline
\end{tabular}

*statistically significant difference, $p<0.05$ (Wilcoxon Signed Ranks Test)

Table 7. Comparing Non-Contrast Enhanced CT versus Contrast Enhanced CT and NonContrast Enhanced PET versus Contrast Enhanced PET at 4 sites in 19 subjects

On the other hand, contrast administrations apparently did not affect the results of PET as evidenced by its SUV-Max values. Non-contrasted PET (NEPET) and Contrasted PET (CEPET) yield similar values of SUV-Max (median \% change in SUV-Max=0). They were not statistically different in the liver $(p=0.814)$, heart $(p=0.876)$, spleen $(p=0.721)$ and bladder $(p=0.44)$. Comparing the effects of contrasts on CT and PET can be easily seen by eyeballing. Thus we were able to show that contrast may change the result of CT (by increasing its HUMean) but not PET (SUV-Max). How this can affect diagnosis or clinical decision is a question that must be explored further. 

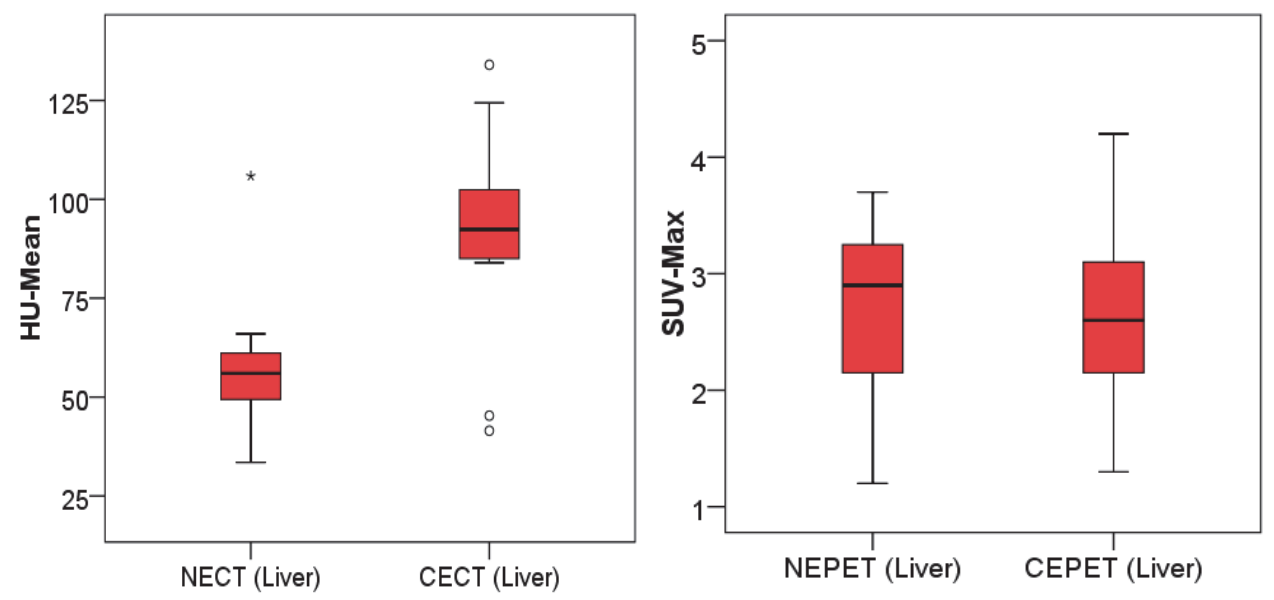

Fig. 6. Side-by-side box \& whisker plots of HU-Mean/SUV Max distributions comparing Non-Contrast Enhanced (left within) and Contrast Enhanced (right within) in CT (left) and PET (right) of the Liver.
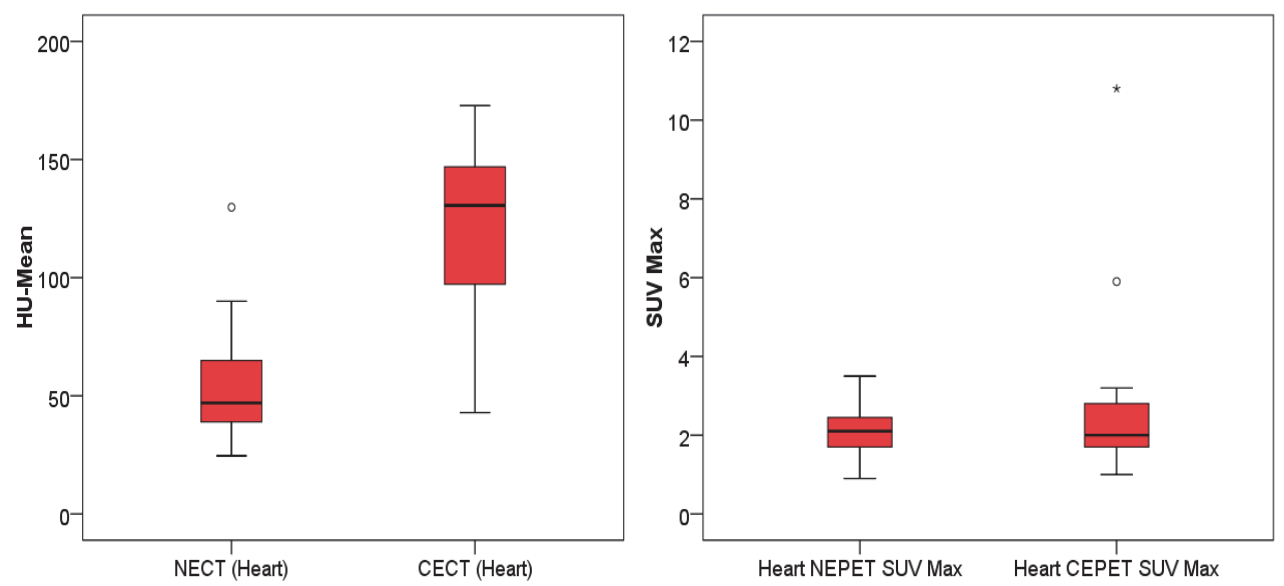

Fig. 7. Side-by-side box \& whisker plots of HU-Mean/SUV Max distributions comparing Non-Contrast Enhanced (left within) and Contrast Enhanced (right within) in CT (left) and PET (right) of the Heart. 

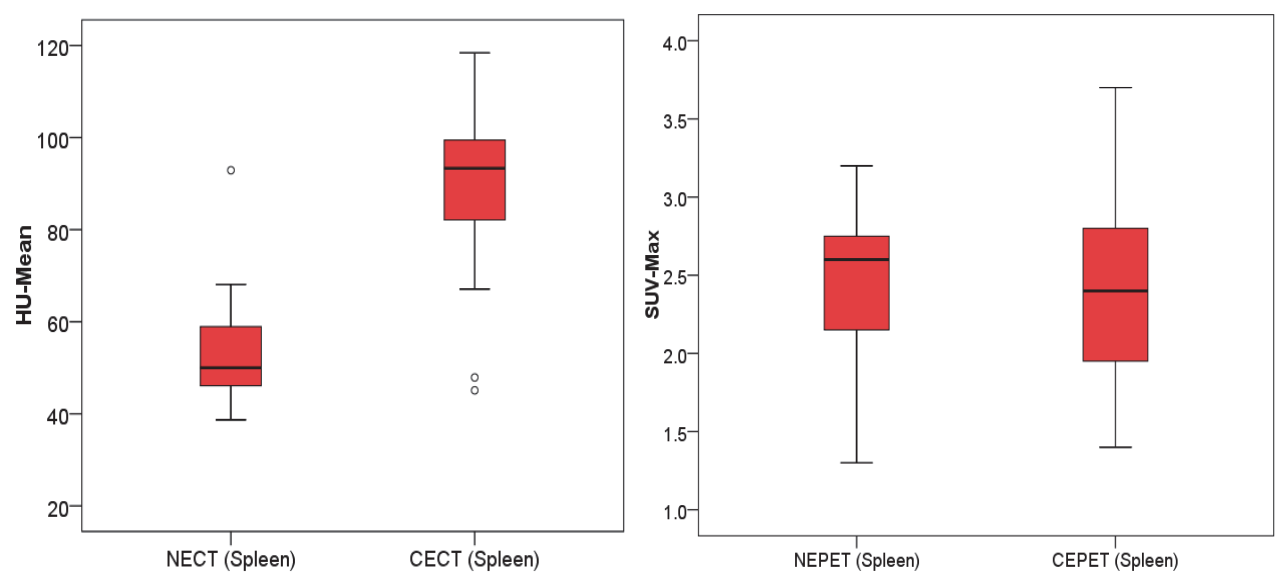

Fig. 8. Side-by-side box \& whisker plots of HU-Mean/SUV Max distributions comparing Non-Contrast Enhanced (left within) and Contrast Enhanced (right within) in CT (left) and PET (right) of the Spleen.
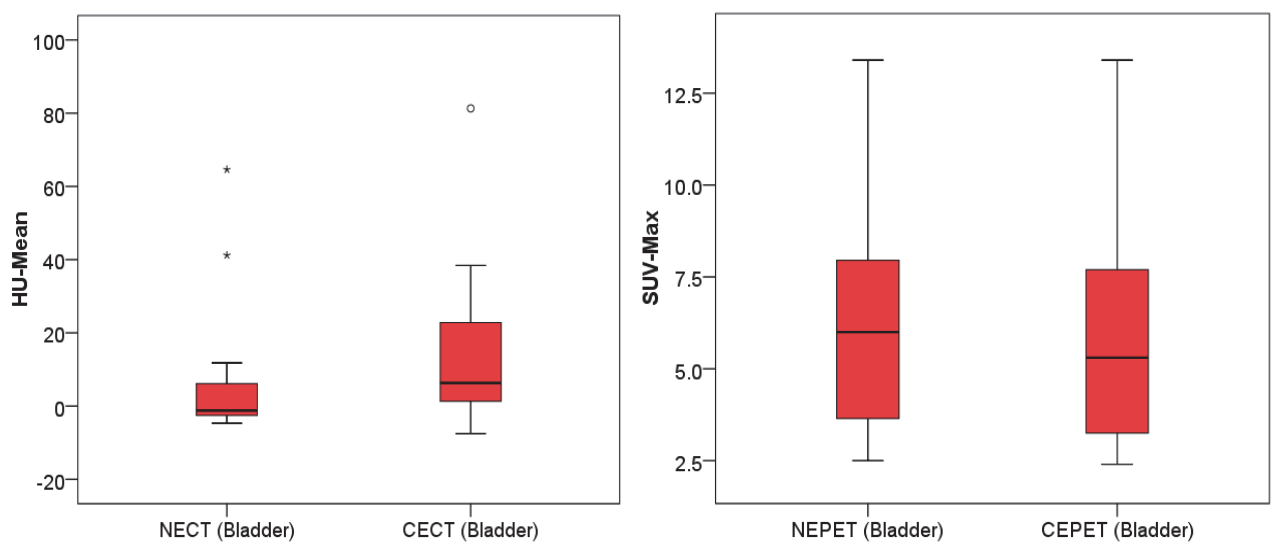

Fig. 9. Side-by-side box \& whisker plots of HU-Mean/SUV Max distributions comparing Non-Contrast Enhanced (left within) and Contrast Enhanced (right within) in CT (left) and PET (right) of the Bladder. 


\section{Conclusions}

In conclusion, contrast enhanced PET/CT study provide detail anatomical imaging descriptions obviating the need for a separate CT study and improve lesion characterization including surrounding organs and vascular involvement. Detail CT informations can be optimized and utilized in patient clinical management. Thus the protocol can be recommended as a first line tool in the investigation of oncology patients.

\section{References}

[1] Rachel Bar-Shalom, Nikolai Yefremov,Ludmila Guralnik, Diana Gaitini, Alex Frenkel, Abraham Kuten, Hernan Altman, Zohar Keidar, Ora Israel. (2003) Clinical Performance of PET/CT in Evaluation of Cancer: Additional Value for Diagnostic Imaging and Patient Management. The Journal of Nuclear Medicine 44(8) 2003

[2] Terence Z. Wong, Erik K. Paulson, Rendon C. Nelson, Edward F. Patz, Jr., R. Edward Coleman (2007) Practical Approach to Diagnostic CT Combined with PET . AJR,188,622-629

[3] Russ A Kuker, Geraldine Mesoloras, Seza A Gulec. Optimization of FDG-PET/CT imaging protocol for evaluation of patients with primary and metastatic liver disease. Semin Surg Oncol, 4, 17.

[4] Ichiya Y, Kuwabara Y, Sasaki M, et al (1996) FDG PET in infectious lesions: the detection and assessment of lesion activity. Ann Nucl Med.10,185- 191.

[5] Wang Y, Chiu E, Rosenberg J, Gambhir S (2007). Standardized Uptake Value Atlas: Characterization of Physiological 2-Deoxy-2-[18F]fluoro-d -glucose Uptake in Normal Tissues. Mol Imaging Biol, 9, 83-90.

[6] Nakamoto Y, Higashi T, Sakahara H, et al (2000). Delayed 18F-fluoro-2-deoxy-D-glucose positron emission tomography scan for differentiation between malignant and benign lesions in the pancreas. Cancer, 89, 2547-2554.

[7] Bisdas S, Baghi M, Smolarz A et al (2007). Quantitative measurements of perfusion and permeability of oropharyngeal and oral cavity cancer, recurrent disease, and associated lymph nodes using first-pass contrast- enhanced computed tomography studies. Invest Radiol, 42,172-17

[8] Sotirios Bisdas, Leon Medov , Mehran Baghi , George N. Konstantinou, Jens Wagenblast, Choon Hua Thng, Thomas J. Vogl, Tong San Koh (2008). A comparison of tumour perfusion assessed by deconvolution-based analysis of dynamic contrast-enhanced CT and MR imaging in patients with squamous cell carcinoma of the upper aerodigestive tract . Eur Radiol,18, 843-85

[9] Khan MA, Coms CS, Brunt EM, et al (2000). Positron emission tomography scanning in the evaluation of hepatocellular carcinoma. J Hepatol, 32, 792-7

[10] Choti MA, Sitzmann JV, Tiburi MF, Sumetchotimetha W, Rangsin R, Schulick RD, Lillemoe KD, Yeo CJ, Cameron JL. (2002) Trends in long-term survival following liver resection for hepatic colorectal metastases. Ann Surg, 235, 759-66.

[11] Elias D, Sideris L, Pocard M, Ouellet JF, Boige V, Lasser P, Pignon JP, Ducreux M (2004). Results of R0 resection for colorectal liver metastases associated with extrahepatic disease. Ann Surg Oncol. 11, 274-80. 
[12] Tanaka S, Noguchi N, Ochiai T, Kudo A, Nakamura N, Ito K, Kawamura T, Teramoto K, Arii S. (2007).Outcomes and recurrence of initially resectable HCC meeting Milan criteria: Rationale for partial hepatectomy as first strategy J Am Coll Surg, 204,1-6

[13] Hanazaki K, Kajikawa S, Shimozawa N, Shimada K, Hiraguri M, Koide N, Adachi W, Amano J. (2001). Hepatic resection for large hepatocellular carcinoma. Am J Surg. 2001;181:347-53.

[14] Patrick Veit-Haibach, Valerie Treyer, Klaus Strobel, Jan D. Soyka, Lars Husmann, Niklaus G. Schaefer, Alois Tschopp, Thomas F. Hany (2010) Feasibility of integrated CT-liver perfusion in routine FDG-PET/CT Abdom Imaging (2010) 35:528-536

[15] Nir Lubezky, Ur Metser, Ravit Geva, Richard Nakache, Einat Shmueli, Joseph M. Klausner, Einat Even-Sapir, Arie Figer, Menahem Ben-Haim (2007) J Gastrointest Surg,11,472-478.

[16] Paulsen SR, Huprich JE, Hara AK (2007). CT enterography: Noninvasive evaluation of Crohn's disease and obscure gastrointestinal bleed. Radiol Clin North Am, 45, 30315.

[17] Fidler J. (2007) MR imaging of the small bowel. Radiol Clin North Am, 45, 31731.

[18] Kinner S, Lauenstein TC (2007). MR colonography. Radiol Clin North Am 45, 37787.

[19] Landeras LA, Aslam R, Yee J. (2007) Virtual colonoscopy: Technique and accuracy. Radiol Clin North Am,45,333.

[20] Mulhall BP, Veerappan GR, Jackson JL. (2005) Meta analysis: Computed tomographic colonography. Ann Intern Med ,142, 635-50.

[21] Johnson CD, Chen MH, Toledano AY, Heiken JP, Dachman A, Kuo MD, et al. (2008) Accuracy of CT colonography for detection of large adenomas and cancers. N Engl J Med, 359, 1207-17

[22] YasudaS, Fujii H, NakaharaT, et al. (2001) 18F-FDGPET detection of colonicadenomas. J Nucl Med, 42, 989-92.

[23] Van Kouwen MCA, Nagengast FM, Jansen JBMJ, Oyen WJG, Drenth JPH. (2005)2(18F)-fluoro-2-deoxy-d-glucose positron emission tomography detects clinical relevant adenomas of the colon: a prospective study. J Clin Oncol 23, 3713-7.

[24] Israel O, Yefremov N, Bar-ShalomR, et al.(2005) PET/CT detection of unexpected gastrointestinal foci of 18F-FDG uptake: incidence, localization patterns, and clinical significance. J Nucl Med, 46, 758-62

[25] Veit-Haibach P, Kuehle CA, Beyer T, et al. (2006) Diagnostic accuracy of colorectal cancer staging with whole-body PET/CT colonography. JAMA, 296, 2590-600.

[26] Low G, Tho LM, Leen E, Wiebe E, Kakumanu S, McDonald AC, et al. (2008). The role of imaging in the pre-operative staging and post-operative follow-up of rectal cancer. Surgeon, 6, 222-31

[27] Shin SS, Jeong YY, Min JJ, Kim HR, Chung TW, Kang HK (2008). Preoperative staging of colorectal cancer: CT vs integrated FDG PET/CT. Abdom Imaging, 33, 270-7. 
[28] Gollub MJ, Schwartz LH, Akhurst T. (2007). Update on colorectal cancer imaging. Radiol Clin North Am, 45, 85-118.

[29] Dave-Verma H, Moore S, Singh A, Martins N, Zawacki (2008). J. Computed tomographic enterography and enteroclysis: Pearls and pitfalls. Curr Probl Diagn Radiol , 37, 279-87.

[30] Hashimoto M, Itoh K, Takeda K, Shibata T, Okada T, Okuno Y, et al. (2008). Evaluation of biliary abnormalities with 64-channel multidetector CT. Radiographics, 28,11934.

[31] Kwon RS, Brugge WR.(2005). New advances in pancreatic imaging. Curr Opin Gastroenterol,2005,21,561-7.

[32] Kwon RS, Scheiman JM. (2006). New advances in pancreatic imaging. Curr Opin Gastroenterol, 22, 512-9.

[33] Robert Dudczak, Tatjana Traub-Weidinger (2010). PET and PET/CT in endocrine tumours. European Journal of Radiology, 73, 481-493

[34] McCollough C.H, Bruesewitz M.R, Kofler J.M. Jr. (2006). CT Dose Reduction and Dose Management Tools: Overview of Available Options. Radiographics, 3, 26.

[35] Valentin, J. (2007) ICRP Publication 103: The 2007 Recommendations of the International Commission on Radiological Protection. Elsevier.

[36] Thie J. (2004). Understanding the standardized uptake value, its methods, and implications for usage. J Nucl Med, 45, 1431-1434.

[37] Martin Allen-Auerbach, Wolfgang A.Weber (2009). Measuring Response with FDGPET: Methodological Aspects . The Oncologist, 14, 369 -377.

[38] MacManus MP, Hicks RJ, Matthews JP et al. (2003). Positron emission tomography is superior to computed tomography scanning for response-assessment after radical radiotherapy or chemoradiotherapy in patients with non-small- cell lung cancer. J Clin Oncol, 21, 1285-1292.

[39] Hawkins DS, Schuetze SM, Butrynski JE et al. (2005). [18F]-Fluorodeoxyglucose positron emission tomography predicts outcome for Ewing sarcoma family of tumors. J Clin Oncol, 23, 8828 - 8834.

[40] P. E. Kinahan, D. W. Townsend, T. Beyer, and D. Sashin, Kinahan PE,Townsend DW, Beyer T, Sashin D. (1998). Attenuation correction for a combined 3D PET/CT scanner Med Phys,25,2046 -2053.

[41] Dizendorf E, Hany TF, Buck A, von Schulthess GK, and Burger C. (2003). Cause and magnitude of the error induced by oral CT contrast agent in CT-based attenuation correction of PET emission studies. J Nucl Med, 44, 732-738.

[42] Dizendorf EV, Treyer V, Von Schulthess GK,Hany TF. (2002). Application of oral contrast media in coregistered positron emission tomography CT. AJR Am J Roentgenol, 179, 477-481

[43] Antoch G, Kuehl H, Kanja J, Lauenstein TC, Schneemann H, Hauth E, et al. (2004) Dual-modality PET/CT scanning with negative oral contrast agent to avoid artifacts: introduction and evaluation. Radiology,230, 879-885.

[44] Antoch G, Saoudi N, Kuehl H, Dahmen G, Mueller SP, Beyer T, et al. (2004). Accuracy of whole-body dual-modality fluorine-18-2-fluoro-2-deoxy-D-glucose positron emission tomography and computed tomography (FDG-PET/CT) for tumor staging in solid tumors: comparison with CT and PET. J Clin Oncol, 22, 43574368 . 
[45] Berthelsen AK, Holm S, Loft A, Klausen TL, Andersen F, Hoigaard L (2005) PET/CT with intravenous contrast can be used for PET attenuation correction in cancer patients. Eur J Nucl Med Mol Imaging. 10, 32:1167-75. 


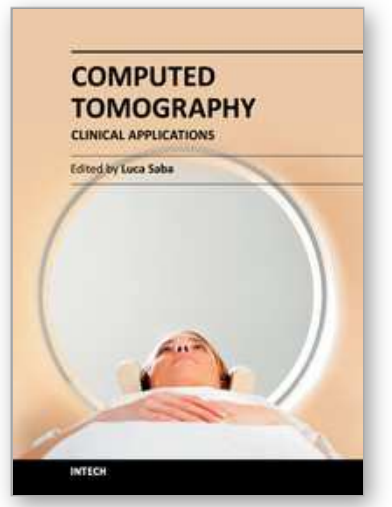

\author{
Computed Tomography - Clinical Applications \\ Edited by Dr. Luca Saba
}

ISBN 978-953-307-378-1

Hard cover, 342 pages

Publisher InTech

Published online 05, January, 2012

Published in print edition January, 2012

Computed Tomography (CT), and in particular multi-detector-row computed tomography (MDCT), is a powerful non-invasive imaging tool with a number of advantages over the others non- invasive imaging techniques. CT has evolved into an indispensable imaging method in clinical routine. It was the first method to non-invasively acquire images of the inside of the human body that were not biased by superimposition of distinct anatomical structures. The first generation of CT scanners developed in the 1970 s and numerous innovations have improved the utility and application field of the $\mathrm{CT}$, such as the introduction of helical systems that allowed the development of the "volumetric CT" concept. In this book we want to explore the applications of CT from medical imaging to other fields like physics, archeology and computer aided diagnosis. Recently interesting technical, anthropomorphic, forensic and archeological as well as paleontological applications of computed tomography have been developed. These applications further strengthen the method as a generic diagnostic tool for non- destructive material testing and three-dimensional visualization beyond its medical use.

\title{
How to reference
}

In order to correctly reference this scholarly work, feel free to copy and paste the following:

Abdul Jalil Nordin, Noraini Abdul Rahim, Fathinul Fikri Ahmad Saad, Ahmad Zaid and Ahmad Zaid Fattah Azman (2012). The Role of Contrast Enhanced Computed Tomography in Integrated Positron Emission Tomography Computed Tomography Study, Computed Tomography - Clinical Applications, Dr. Luca Saba (Ed.), ISBN: 978-953-307-378-1, InTech, Available from: http://www.intechopen.com/books/computedtomography-clinical-applications/the-role-of-contrast-enhanced-computed-tomography-in-integrated-positronemission-tomography-compute

\section{INTECH}

open science | open minds

\section{InTech Europe}

University Campus STeP Ri

Slavka Krautzeka 83/A

51000 Rijeka, Croatia

Phone: +385 (51) 770447

Fax: +385 (51) 686166

www.intechopen.com

\section{InTech China}

Unit 405, Office Block, Hotel Equatorial Shanghai

No.65, Yan An Road (West), Shanghai, 200040, China

中国上海市延安西路 65 号上海国际贵都大饭店办公楼 405 单元

Phone: +86-21-62489820

Fax: $+86-21-62489821$ 
(C) 2012 The Author(s). Licensee IntechOpen. This is an open access article distributed under the terms of the Creative Commons Attribution 3.0 License, which permits unrestricted use, distribution, and reproduction in any medium, provided the original work is properly cited. 